\title{
DECISION-MAKING IN THERAPEUTIC GROUPS
}

\section{MARIAN F. FATOUT}

The major focus in the group literature on decision-making processes has been in the area of task groups. Relatively little attention has been given to these processes in relation to therapeutic groups. There are linkages between the stages of group decision making and group development which can add understanding and knowledge to practice in therapeutic groups.

A dimension of group interaction which has been given relatively little attention in the literature on therapeutic groups is the decision-making process. This process is a part of all group life. It is accepted as essential to task oriented groups, but its importance is not as clearly recognized in regard to therapeutic groups.

This distinction between task oriented groups and therapeutic groups is defined by Toseland and Rivas (1984) and others (Klein, 1972; Jennings, 1950; Hartford, 1971; Bales, 1950). The bonds, roles, communication patterns, amount of member self-disclosure, bases for evaluation, and other characteristics differ for therapeutic groups and task groups.

Two major distinguishing characteristics are the nature of the bonds and the bases of evaluation. In a therapeutic group, the bonds result from the interaction between members; in a task group, the bonds result from the interest of commitment to a task. Evaluation of the success of a treatment group is 'based on members meeting treatment goals'; while in a task group, success is 'based on members accomplishing task, mandate or producing a product' (Toseland and Rivas, 1984, p. 16).

Conflict has been recognized as an integral part of both task and therapeutic groups and is usually highlighted in the decision-making process. For therapeutic groups, conflict is viewed as the core of any group activity and as the energy which moves the group along (Wilson and Ryland, 1943) and as a source of growth and change for the members (Levine, 1979).

In reviewing research on decision-making focused on 'work groups' or task groups, it becomes evident that some findings related to stages of decision-making are directly applicable to the developmental stages of the social work group. These developmental stages have been described by many social workers and now can be linked to research 
which identifies stages of the decision-making process. This linking adds more validity to the belief of many social workers that by viewing the decision-making process in cross-section, one can expect to identify the phase or stage of the group's development by the way decisions are being made in that group.

\section{A model of stages in decision-making}

In small group research conducted by sociologists and other behavioural scientists, conflict was viewed as a single act. An exception to this was Baxter (1982), who conceptualized conflict not as single acts, but rather as an episode. 'An episode, then, is a set of sequential utterances with a perceived beginning point and end point' (Baxter, 1982, pp. 24). From this perspective, a conflict episode is initiated with the expression of a disagreement. Once this has happened, there are two possible outcomes: the group may reach a resolution of the conflict issue, or it may abandon the conflict issue through a shift of topics before closure can occur (Baxter, 1982). This conflict episode, including the expression of disagreement and the discussion which follows, demonstrates an important aspect of conflict management, the 'having a fight' episode.

Based on the research of others (Ellis and Fisher, 1975; Fisher, 1970; Valentine and Fisher, 1974), Baxter (1982) developed a model of stages in decision-making. The initial stage was characterized by a generally low expression of disagreement. When disagreement did occur in the initial stage, others were not inclined to reciprocate with counterdisagreement. The usual form of response of others was either agreement or ambiguous reactions.

In the middle stage, there is an increased expression of disagreement and argument. The episodes are more apt to be characterized by disagreement and information intended to persuade group members. Group disagreement acts peak in the middle stage, and tend to decrease in frequency in the final stage.

There is also a different quality to the disagreement which occurs in the final stage. Now, unlike the polarized assertions of the middle stage, the group members become involved in critical testing and interpretation of relevant information. The behaviour of group members in the final stage suggests that trust is very much a part of the group atmosphere and that interpersonal relationships and interactions are no longer a primary factor in the conflict situations.

The importance of resolution of the conflict is noted by Baxter (1982). He points out that when the groups use 'fight, flight', the end result will probably be superconflict of stockpiled issues. Superconflicts 
are very difficult to resolve in a constructive way.

In order to have a framework for analyzing stages of group development and decision-making, a classification of types of conflict resolution is essential. Eubank (1932) provided a very meaningful way of viewing conflict and its resolution, one that is applicable to therapeutic groups. He classified societal action into two categories, opposition and accommodation. These two broad categories of interaction can be divided into five types of resolutions: elimination; subjugation; compromise; alliance; and integration.

Elimination involves a situation in which members may combat each other, each seeking to win and, if necessary, rid the group of opposing factions or individuals. When subjugation is used, the strongest subgroup or individual may force others to accept its point of view and thus dominate the opposition. When compromise is used, the strength of the competing subgroups or individuals is approximately equal, each may give up something to safeguard the activity or life of the group. Alliance involves subgroups or individuals who may maintain their independence, but combine to achieve a common goal. Integration involves the group as a whole arriving at a solution that not only satisfies each member, but is better than any of the contending suggestions. All of these methods of conflict resolution utilize both verbal and non-verbal processes. There may be deliberations, physical violence, and other threatening and non-threatening behaviour utilized in the decision-making process (Lowy, 1973).

One is struck by the similarity between the stages of decisionmaking and the phases of group development which are described in the literature on work with therapeutic groups (Levine, 1979; Northen, 1988). There is a natural fit between the development of the group involving the characteristics of interaction at different points throughout the life of the group and the stages occurring in group decisionmaking as identified by Baxter (1982). Since there is this linkage, it can be expected that Eubank's (1932) type of conflict resolution can also be related to the phase of development of a group.

\section{Decision-making, group development and conflict resolution styles}

Coinciding with the researchers' (Ellis and Fisher, 1970; Fisher, 1970; Valentine and Fisher, 1974) findings with regard to stages of decisionmaking are the findings of many behavioral scientists with regard to the developmental stages of small groups. There are so many conceptualizations of these stages and so much overlap in the boundaries of a 
specific stage that the focus here will be on only two of the frameworks, that of Northen (1988) and Levine (1979).

In the description of the decision-making in the initial stages, it is noted that little disagreement occurs. When it does occur in this stage, others do not respond with disagreement but are inclined to ignore the comments, pass over it, or simply agree with the statement.

The literature on group development (Levine, 1979; Northen, 1988) describes what is occurring with new members as they enter the group. Members are described as anxious, uncertain, tense, and selfconscious.

Relationships of members with each other evolve out of the efforts to adapt to the expectations for the role of members in the particular group (Northen, 1988, pp. 185).

Verbal communication is also described as not having developed a pattern. It is often scattered, diffuse, and lacking in continuity.

As a person enters a new group, he/she scans the situation for signs that indicate to what extent he/she is welcome. There is great sensitivity to non-verbal communications, such as tone of voice, facial expressions, or gestures. These, too, may provide very potent messages to the potential member.

Levine (1979) reminds us of the trust dilemma which occurs during the initial phase of the group. Each member is struggling with whether to trust or mistrust the group and the other members. Trust develops as the person gains confidence that 'they accept his presence, his initiative and the substance of what he says' (Levine, 1979, pp. 95). A major fear is that of being rejected or being harmed or punished in the group.

More specifically, Levine (1979) focuses on the 'pseudo-interaction' which happens in the beginning group stage. He notes: 'More aggressive or more anxious members can tend to dominate the discussion during this phase' (LevIne, 1979, pp. 96). Other members not only allow this, but often encourage it so they can observe the consequences of this behaviour.

Most members display 'company manners'. Their attempt to check their fears often results in a tendency to be overly nice. Much of the talking and other behaviours during this stage are seen by Levine (1979) as risking and responding to risks. At the same time, much of their activity is intended to keep the situation safe and away from anxiety-provoking issues. 'When many group members join in these discussions they are casting votes for maintaining a safe and distant atmosphere' (Levine 1979, pp. 97).

So the literature on group development generally agrees that 
during the beginning phase of the group, overt conflict is usually nonexistent, just as was found in the research on stages of decision-making (Baxter, 1982). Since overt conflict does not often occur, Eubank's types of conflict are not applicable in this stage.

An example of this beginning phase process occurred when a group of women, who had just returned from a stay in a state mental hospital, formed a group in the local mental health center. In the second group session, one of the more aggressive members announced that they should all bring sewing or other handwork to the next session. One or two women expressed disagreement using non-verbal communication; one shook her head 'no'; the other wrinkled her face, demonstrating her dislike of the suggestion. When the worker gave the members opportunities to express their disagreement verbally, everyone was in agreement or they remained silent.

This decision-making might be viewed as 'false consensus', and there may be a question about worker intervention in this process. Yalom (1985), Levine (1979), and Northen (1988) suggest that in the beginning group stage it is most useful to the process to minimize differences until some cohesion has developed. So, worker intervention would not be seen as helpful to the group.

The middle stage of the decision-making process is identical to phases described in the group development literature. The types of behaviors and interactions between the members are the same as those occurring in the disatisfaction and power phase (Northen, 1988) or the inclusion phase (Levine, 1979).

Conflict is a major characteristic of this stage of decision-making and of this phase of group development. Conflict in its broadest form arises as a result of a variety of situations, pulls, pushes, and struggles, not just from decision-making or the stages of the group. Bernstein (1973, p. 72) says: 'Differences arise not only from intra-psychic sources, but also from stages of development, roles, reference groups and other factors'.

Whitaker and Lieberman's (1964) concept of conflict also adds to the understanding of member differences and their possible relationship to the decision-making processes and the development of the group over time. Their concept of 'focal-conflict' would seem to support and explain the dynamics of 'beginnings' and later stages both of decisionmaking and of the group. The idea of the 'disturbing motive' and the 'reactive motive' leading to the solution may be the more specific basic steps leading to these broader areas of conflict in group decision-making and stages of development of the group.

In group development literature it is noted that, at first, only the 
aggressive members who are comfortable with hostility and aggression can express their disagreements. 'Conflicts during the inclusion phase are the most dramatic and fearsome conflicts in a group because losing a conflict is tantamount to rejection' (Levine, 1979, pp. 153). Members do not partialize their opinions or feelings; if their side of the conflict is rejected, they feel rejected by the group.

Within the group development framework, this type of behavior and member-to-member interaction is very understandable. It is during this phase of the group that members are testing each other, the worker, and themselves in relation to others. They are looking for their position and role in the group. Cohesion can be expected to grow as a result of these experiences.

Sometimes in a single example one sees movement of the group from this stage to the next stage is decision-making. A group of hostile 'acting out' adolescent girls were planning a trip to a cabin in the mountains. Two of the girls asked the worker who would be picked up in the van first. The worker responded that they would be picked up in the usual rotation order (each girl having the opportunity to be first). At the next group session, there was a great deal of anger and hostility expressed between the two major subgroups in the group, and the worker's answer to the two girls had given power to the weaker subgroup. They were the members who would be picked up first for the trip. The worker said that she had made a mistake in deciding for the group and that it was important that they make the decision about the order in which they would be picked up.

The group members began to discuss and argue with each other as they tried to reach a resolution. The person leading the discussion was a member of the more powerful subgroup. Finally, a vote was taken and the group decided to go with the original decision. Evidently, the weaker subgroup had developed an alliance with members not strongly attached to either subgroup.

A vote was taken. There was a clear decision, but there was no resolution of the conflict. The members 'acted out' their anger. Some of them did so by walking a dangerous ledge over the stairwell; others rolled pool balls down the stairway toward the glass door at the bottom.

In an attempt to bring the group to some resolution, the social worker again brought them together to try to resolve the issue. To no avail! They reached a similar decision, but, again, no resolution of the conflict. They were still very angry and continued to 'act out'. Some of the members remained in the clubroom area, others straggled downstairs to get into the van. This behaviour was clearly against their rules.

By the time the worker had locked the building and reached the 
van, the girls were seated and blowing the horn. As the worker approached, the members locked the car doors. As she unlocked the door with a key, members again depressed the lock. Finally, when the worker non-verbally expressed her helplessness by indicating 'I give up', the members unlocked the door. The girls were angry at each other, but the worker had influenced the decision-making process and now all of the anger seemed displaced on her.

It is recognized that many other dynamics are underlying this incident in the group. Bernstein (1973) suggests that if an adolescent has not resolved his/her struggle with authority figures, this may also precipitate and/or play into the resulting struggle. Levine (1979) identifies a major crisis which must occur in all groups as 'the authority crisis', which certainly fits with the interaction occurring in the situation just described.

The worker sat down in the seat; members were waiting for a negative response to their behavior. The worker said, 'I do not understand why you could not reach a decision this time; I have see you do it before'. The members were silent and the worker began to take the girls home. After driving a very short distance, members asked the worker to park for a moment so that they could make a decision. One of the members asked if the seats in the van could be folded down on the day they went to the mountains. This would make a flat surface in the back of the van. She and others were assured by the worker that it could be done if that was what they wanted. Everyone quickly agreed. The weaker group could be picked up first and the more powerful subgroup could still manoeuvre the seating arrangement because of the lack of boundaries provided by the removal of the seats.

The close, warm feelings which followed this experience were evident. More feelings of individual competence and cohesion were noted immediately. Levine (1979) has stated that conflict resolution is the building blocks by which inclusion of the entire group occurs, resulting in cohesion. A decision had been made and a conflict resolved.

The group had begun the session using a more primitive method of conflict resolution, subjugation, and alliance; before the session ended, the group had moved to the integration method. This method is viewed as the most desirable one for conflict resolution since it satisfies each member better than any of the contending suggestions (Eubank, 1932). Along with change in conflict resolution came a movement of the group from the dissatisfaction and power/conflict phase, described earlier, to the mutuality and work phase of group development (Northen, 1988).

It can be expected that integration will be the method of conflict 
resolution used most often in the mutuality and work phase because of the characteristics of interaction among the members. Again, there is a match between this phase of mutuality and work (Northen, 1988) or the mutuality phase (Levine, 1979) and the final decision-making stage of Fisher (1970). The characteristics of this decision-making stage involve trust as an essential ingredient of the group atmosphere and interactions, and interpersonal relations are no longer primary factors in the conflict situation.

In the group development framework, very similar characteristics are described. Two major characteristics identified in the literature are:

i. the emergence of a cohesive group in which members are interdependent;

ii. the use of the group for working through problems (Northen, 1988).

Now, there is no longer the polarized and individual subgroup processes, but rather a total group orientation. Another characteristic of the group is acceptance and utilization of differences for work on problemsolving activities. Northen (1988, p. 260) writes: 'The predominant qualities of relationship in this phase are trust, acceptance and a search for intimacy and differentiation'. Members feel emphathy for each other and they feel understood by others. They no longer have to defend themselves against the thoughts and feelings of other members.

Conflict continues to occur in this phase, but generally it is resolved more quickly. 'Survival in the group is no longer at stake in each conflict' (Levine, 1979, p. 213). Power is shared by all. So, with the threat of rejection no longer of concern, members are able to express more fully their side of the conflicts and also be more free to listen to others.

The conflict resolution of a group of adolescent girls further demonstrates the process as the problem solving or mutuality phase continues. Members in each group in the agency were given a small amount of money to spend as they wished for Christmas. The group needed to decide what they would do with their money. They talked of buying treats for themselves; some wanted simply to take the money home. There were many suggestions for the use of the money. After a rather heated discussion, one member suggested that they draw names and buy gifts for each other. Everyone was in immediate agreement. This suggestion did not seem to include their previously stated desires about spending, but was enthusiastically accepted.

After drawing names, the girls left for the variety store, bought their gifts, and wrapped them. During their gift giving to each other, it 
became evident that the conflict resolution process utilized had been that of integration. After drawing names, the members had found out who had their name and had made suggestions of possible gifts they wanted. The girls who had wanted treats received them and others were given what they had suggested during the discussion. Two girls from very low income homes had gifts to open at the party, but they had shared with the person buying the gifts that they really wanted something to take home to mother for Christmas. The criteria for the integrative method of conflict resolution had been met. These were members who truly cared and empathized with each other.

\section{Conclusion}

Social workers can better understand the process and provide more useful assistance to members and the group in the accomplishment of their goals by giving more attention to decision-making and conflictresolution processes. Because of the close linkage of decision-making stages and group development, the worker may have opportunity to assist groups to make decisions which are satisfying to the members and at the same time help the group to move along in its development.

\section{References}

Bales, R. (1950) Interaction Process Analysis: A Method For the Study of Small Groups. Reading, MA: Addison-Wesley.

Baxter, L.A. (1982) 'Conflict management: An episodic approach', Small Group Behavior, 13, pp. 23-42.

Bernstein, S. (1973) 'Conflict and group work' in S. Bernstein (ed.) Explorations in Group Work Boston: Milford House.

Ellis, D. and Fisher, B.A. (1975) 'Phases of conflict in small group development: A marker analysis', Human Communication Research, 1, pp. 95112.

Eubank, E. (1932) The Concepts of Sociology. New York: D.C. Health and Company.

Fisher, A. (1970) 'Decision-emergence: Phases in group decision-making', Speech Monographs, 37, pp. 53-66.

Fisher, A. (1974) Small Group Communication. New York: McGraw Hill.

Hartford, M.E. (1971) Groups in Social Work. New York: Columbia University Press.

Jennings, H. (1950) Leadership and Isolation, 2nd Edition. New York: Longman, Inc.

Klein, A. (1972) Effective Group Work New York: Association Press.

Levine, B. (1979) Group Psychotherapy: Practice and Development. Englewood Cliffs, NJ: Prentice-Hall. 
Lowy, L. (1973) 'Decision-making and group work', in S. Bernstein (ed.). Explorations in Groups. Boston: Milford House.

Northen, H. (1988) Social Work With Groups, 2nd Edition. New York: Columbia University Press.

Toseland, R. and Rivas, R.F. (1984) An Introduction to Group Work Practice. New York: MacMillan Publishing Company.

Valentine, K. and Fisher, B.A. (1974) 'An interaction analysis of verbal innovative deviance in small groups', Communication Monographs, 41, pp. 413-420.

Whitaker, D.S. and Lieberman, M.A. (1964) Psychotherapy Through the Group Process. New York: Atherton Press.

Wilson, G. and Ryland, G. (1949) Social Group Work Practice. Cambridge, MA: The Riverside Press.

Yalom, I.D. (1985) The Theory and Practice of Group Psychotherapy, 3rd Edition. New York: Basic Books. 